aminophylline-treated animals is not known. To our knowledge cortisol effects on survival have not been studied in rabbits delivered at 27.0 days.

\section{CONCLUSION}

It appears likely that aminophylline is at least as effective as cortisol (and possibly more so) in accelerating maturation of fetal lungs as evidenced by survival time, phosphatidylcholine content, and lung pressure-volume characteristics. Toxicity of aminophylline administered prenatally to the mother has not been investigated, but in the present study no major evidence of fetal toxicity was observed.

\section{REFERENCES AND NOTES}

1. Arvidson, G. A. E.: Structural and metabolic heterogeneity of rat liver glycerophosphatides. Eur. J. Biochem., 4: 478 (1968).

2. Barrett, C. T., Sevanian, A., Lavin, N., and Kaplan, S. A: Role of adenosine $3^{\prime}, 5^{\prime}$-monophosphate in maturation of fetal lungs. Pediat. Res., 10: 621 (1976).

3. Bartlett, G. R.: Phosphorus assay in column chromatography. J. Biol. Chem., 234: 466 (1959).

4. Budin, P.: Le nourrisson, alimentation et hygiene des enfants delilés-enfants nés à term (Octave Doin, Paris, 1900).

5. Carson, S. H., Taeusch, H. W., and Avery, M. E.: Inhibition of lung cell division after hydrocortisone injection into fetal rabbits. J. Appl. Physiol., 34: 660 (1973)

6. Folch, J., Lees, M., and Sloan-Stanley, G. H.: A simple method for isolation and purification of total lipids from animal tissues. J. Biol. Chem., 226: 497 (1957).

7. Fujiwara, T., Adams, F. H., El-Salawy, A., and Sipos, S.: "Alveolar" and whole lung phospholipids of newborn lambs. Proc. Soc. Exp. Biol. Med. 127: 962 (1968).

8. Gilden, C., Sevanian, A., Tierney, D. F., Kaplan, S. A., and Barrett, C. T.: Regulation of fetal lung phosphatidyl choline synthesis by cortisol: Role of glycogen and glucose. Pediat. Res., 11: 845 (1977).

9. Howard, E.: Reductions in size and total DNA of cerebrum and cerebellum in adult mice after corticosterone treatment in infancy. Exp. Neurol., 22: $191,(1968)$.

10. Karotkin, E. H., Kido, M., Cashore, W. J., Redding, R. A., Douglas, W. J., Stern, L., and Oh, W.: Acceleration of fetal lung maturation by aminophyl- lin in pregnant rabbits. Pediat. Res., 10: 722 (1976).

11. Kotas, R. V., Mims, L. C., and Hart, L. K.: Reversible inhibition of lung cell number after glucocorticoid injection into fetal rabbits to enhance surfactant appearance. Pediatrics, 53: 358 (1974).

12. Lavin, N., Rachelefsky, G., and Kaplan, S. A.: Inhibition of cyclic AMP phosphodiesterase in human lymphocytes by physiological concentrations of hydrocortisone. Horm. Metab. Res., 7: 253 (1975).

13. Liggins, G. C., and Howie, R. N.: A controlled trial of antepartum glucocorticoid treatment for prevention of the respiratory distress syndrome in premature infants. Pediatrics, 50: 515 (1972).

14. carbohydrate metabolism. Endocrinology, 26: 309 (1940).

15. Motoyama, E. K., Orzalesi, M. M., Kikkawa, Y., Kaibara, M., Wu, B. Zigas, C. J., and Cook, C. D.: Effect of cortisol on the maturation of fetal rabbit lungs. Pediatrics, 48: 547 (1971).

16. Rousseau, G. G., Higgins, S. J., Baxter, J. D., Gelfand, D., and Tomkins, G. M.: Binding of glucocorticoid receptors to DNA. J. Biol. Chem., 250: 6015 (1975).

17. Schmidtke, J., Wienker, T., Flugel, M., and Engel, W.: In vitro inhibition of cyclic AMP phosphodiesterase by cortisol. Nature, 262: 593 (1976).

18. Shannon, D. C., Gotay, F., Stein, I. M., Rogers, M. C., Todres, I. D., and Moylan, F. M. B.: Prevention of apnea and bradycardia in low-birthweight infants. Pediatrics, 55: 589 (1975).

19. Shapiro, S. Some physiologic, biochemical and behavioral consequences of neonatal hormone administration: Cortisol and thyroxin. Gen. Comp. Endocrinol., 10: 214 (1968).

20. Snedecor, G. W., and Cochran, W. G.: Statistical Methods, Ed. 6 (Iowa State University Press, Ames, Iowa, 1967).

21. Taeusch, H. W. Jr., Heitner, M., and Avery, M. E.: Accelerated lung maturation and increased survival in premature rabbits treated with hydrocortisone. Amer. Rev. Resp. Dis., 105: 971 (1972)

22. Uauy, R., Shapiro, D. L., Smith, B., and Warshaw, J. B.: Treatment of severe apnea in prematures with orally administered theophylline. Pediatrics, 55: 595 (1975).

23. Wellman, K. F., and Volk, B. W.: Fine structural changes in the rabbit placenta induced by cortisone. Arch. Pathol., $94: 147$ (1972).

24. Wicks, W. D.: The mode of action of glucocorticoids. In: Biochemistry of Hormones, M. T. P. International Review of Science, Biochemistry, Series 1, Vol. 8, pp. 211-242 (University Park Press, Baltimore, 1974).

25. This research was supported in part by a grant from the California Research and Medical Education Fund of the California Lung Association.

26. Requests for reprints should be addressed to: Cynthia T. Barrett, M.D., Department of Pediatrics, UCLA School of Medicine, Los Angeles, CA 90024 (USA).

27. Received for publication January 10,1977

28. Accepted for publication March 28, 1977.

\title{
Inotropic Response of the Neonatal Canine Myocardium to Dopamine
}

\author{
DAVID J. DRISCOLL, ${ }^{(22)}$ PAUL C. GILLETTE, EDWARD G. EZRAILSON, AND ARNOLD \\ SCHWARTZ \\ Departments of Cell Biophysics and Pediatrics, Section of Cardiology, Baylor College of Medicine; Texas \\ Children's Hospital; and The Fondren-Brown Cardiovascular Center of The Methodist Hospital, Houston, Texas,
}

\section{Summary}

The inotropic responsiveness of the developing myocardium to dopamine and isoproterenol was evaluated using isolated, perfused ventricles and atrial strips from puppies ages $15 \mathrm{hr}$ to 33 days. Responses were compared to those in adult animals.

The maximum percentage of increase of left ventricular $\mathrm{dF} / \mathrm{dt}$ increased from $12 \pm 5$ (mean \pm SEM) at 0-7 days $(n=6)$ to $100 \pm 40$ at 21-33 days $(n=3)$ of postnatal age. At 7-14 days $(n=4)$ and 15-20 days $(n=5)$ of age the maximum percentage of increase of left ventricular $\mathrm{dF} / \mathrm{dt}$ was $28 \pm 10$ and $39 \pm 17$, respectively. Puppy ventricle responded to isoproterenol at all ages equally (maximum percentage increase of left ventricular $\mathrm{dF} / \mathrm{dt}=46 \pm 13)$. 
Atrial muscle strips from puppies, ages $15 \mathrm{hr}$ to 35 days $(n=$ 22), and adult dogs $(n=19)$ demonstrated equal responsiveness to dopamine as well as to isoproterenol. The maximum percentage of increase of $\mathrm{dF} / \mathrm{dt}$ was $117 \pm 18$ with dopamine. Maximum percentage of increase of $\mathrm{dF} / \mathrm{dt}$ with dopamine after propranolol $\left(10^{-7} \mathrm{M}\right)$ was $52 \pm 18$. Haloperidol $\left(1.10^{-7}-2.10^{-6} \mathrm{M}\right)$ did not alter responsiveness of atria to dopamine.

\section{Speculation}

This study demonstrates that isolated puppy ventricle becomes increasingly responsive to the inotropic effect of dopamine with increasing age. The data suggest that the major inotropic effect of dopamine in puppy ventricle is mediated through release of norepinephrine and is consistent with previous reports of decreased levels of releasable norepinephrine in ventricular myocardium but adequate stores of norepinephrine in atrial muscle of immature animals.

Dopamine, a natural precursor of norepinephrine, is a clinically useful inotropic agent $(3,10,11,18)$. Although it has been studied extensively in the mature animal, little information is available concerning the effect of dopamine on the neonatal myocardium.

Neonatal ventricular myocardium has fewer contractile elements per unit mass of myocardium than does adult ventricular myocardium $(5,16)$. Furthermore, the sympathetic innervation of the ventricular myocardium is not complete at birth in many species and ventricular stores of norepinephrine are reduced $(5-7,9,12,17)$. Therefore, modulation of contractility is more limited in the immature than in the mature myocardium and responses to indirect $\beta$-adrenergic agonists, such as dopamine, could be expected to be reduced in young animals $(1,4,13,14)$.

The purpose of this study was to determine the response of the developing neonatal canine myocardium to dopamine.

\section{MATERIALS AND METHODS}

Isolated perfused puppy ventricle and atrial strips from puppies and adult dogs were used for the experimental preparations. Animals were selected without preference for breed or sex. Preparations were made in duplicate, using one as the control and the other as the experimental preparation. The data was statistically analyzed using the $t$-test for independent means.

\section{ISOLATED PERFUSED VENTRICULAR PREPARATION}

The animals used for this study were as follows: six puppies, ages 0-7 days; four puppies, ages 7-14 days; five puppies, ages 14-21 days; three puppies, ages 21-33 days; one adult cat; two adult rabbits. Without anesthesia, rapid cervical dislocation was performed and the heart was excised quickly and perfused via the aortic root on a constant flow device. The perfusate consisted of Krebs' solution with the following millimolar concentrations: sodium chloride 118 , potassium chloride 4.7 ; calcium chloride 2.5 ; sodium bicarbonate 25 ; magnesium chloride 0.5 ; sodium hypophosphate 1 ; and glucose 11.1. The $\mathrm{pH}$ was maintained between 7.30 and 7.50 , and the temperature at $37^{\circ}$. The Krebs' solution was bubbled with $95 \% \mathrm{O}_{2}$ and $5 \% \mathrm{CO}_{2}$. Fresh solution was prepared each day. The heart was perfused at $20 \mathrm{cc} / \mathrm{min}$ using a Harvard constant flow peristaltic pump. Both atria were excised, the pulmonary artery was vented, the atrioventricular (AV) valves were opened, and the AV node was crushed. The tips of platinum pacing wires were inserted into the myocardium of the right ventricular outflow region and the right $A V$ valve ring. The preparations were paced at a rate of $120-130$ beats/ min, using a Nuclear Chicago stimulator. The pacing voltage used was $10 \%$ above threshold voltage, and ranged from $0.5-$ $0.75 \mathrm{~V}$. The pulse duration was $3 \mathrm{msec}$. Pacing voltage and the duration of the stimulus were monitored with a Tektronix type 564 storage oscilloscope.
A small rat ventricle type of Walton-Brodie strain gauge arch (John L. Waren, Charleston, SC) was sutured to the free wall of the left ventricle, carefully avoiding coronary artery obstruction. Isometric force of contraction and its first derivative $(\mathrm{dF} /$ dt) as well as aortic perfusion pressure were monitored continuously on a Grass polygraph model 7 . An operational amplifier derivative circuit was used to determine $\mathrm{dF} / \mathrm{dt}$. Aortic perfusion pressure was measured using a Statham P23db pressure transducer connected proximal to the aortic cannula.

Drugs were infused using a Harvard infusion/withdrawal pump into a port immediately proximal to the aortic cannula Commercially available dopamine hydrochloride solution that contains sodium bisulfite as an antioxidant was used. In two atrial muscle strip experiments, fresh solution of dopamine prepared by dissolving crystals of dopamine hydrochloride in Krebs' solution was used. L-Isoproterenol solution was prepared from crystals of L-isoproterenol hydrochloride dissolved in Krebs' solution. All drugs were diluted in Krebs' solution before infusion.

Dose-response curves were obtained using dopamine concentrations of $10^{-9}-10^{-4} \mathrm{M}$ or isoproterenol concentrations of $10^{-10}-10^{-5} \mathrm{M}$.

\section{ISOLATED ATRIA}

The animals used for this study were as follows: 8 puppies, ages $0-7$ days; 6 puppies, ages $7-14$ days; 4 puppies, ages 1421 days; 4 puppies, ages $21-33$ days; and 19 adult dogs.

After rapid cervical dislocation, the heart was excised quickly, immersed in Krebs' solution, and a left atrial strip prepared. One end of the left atrial strip was impaled with a pair of platinum needle electrodes and the other end attached to a Statham force transducer $(350 \mathrm{ohms})$. The preparation was then immersed in a bath containing Krebs' solution. The tension of the preparation was adjusted for maximum force of contraction. The bath was rinsed every $10 \mathrm{~min}$. Strips were paced at a rate similar to the in vivo depolarization rate (120-180 beats/min), using $0.5-0.75 \mathrm{~V}$ and a 3-msec pulse duration. The pacing voltage and duration of the stimulus were monitored with a Taktronix type 564 storage oscilloscope. Isometric force of contraction and $\mathrm{dF} / \mathrm{dt}$ were continuously recorded on a Grass polygraph model 7. An operational amplifier derivative circuit was used to determine $\mathrm{dF} / \mathrm{dt}$. Drugs were added to the bath and mixed by a constant stream of $95 \% \mathrm{O}_{2}$ and $5 \% \mathrm{CO}_{2}$. Dopamine concentrations of $10^{-8}-10^{-3} \mathrm{M}$ and isoproterenol concentrations of $10^{-9}-10^{-5} \mathrm{M}$ were employed. Propranolol $\left(10^{-7} \mathrm{M}\right)$ and haloperidol $\left(10^{-7}\right.$ and $\left.10^{-6} \mathrm{M}\right)$ were used for blocking experiments. Blocking experiments were done using atrial strips obtained from adult dogs. The order of drug application was isoproterenol $\rightarrow$ dopamine $\rightarrow$ blocking agent $\rightarrow$ isoproterenol $\rightarrow$ dopamine. In seven preparations, a $1 \%$ sodium bisulfite solution was used as a control drug.

\section{RESULTS}

\section{ISOLATED VENTRICULAR PREPARATIONS}

The inotropic response (percentage of change of $\mathrm{dF} / \mathrm{dt}$ ) of isolated puppy ventricle to dopamine increased with increasing postnatal age (Figs. 1 and 2). Adult levels of responsiveness appeared at 21-33 days of age. Puppy ventricle less than 7 days old exhibited essentially no response to dopamine. Reserpinized adult rabbit ventricle responded in the same manner as puppy ventricle less than 21 days of age (Fig. 2). The ventricles of puppies at all ages were equally responsive to isoproterenol.

\section{ATRIAL STRIP PREPARATIONS}

The inotropic response (percentage change of $\mathrm{dF} / \mathrm{dt}$ ) of atrial strips from canines of all ages to dopamine as well as to isoproterenol was equal (Fig. 3). 


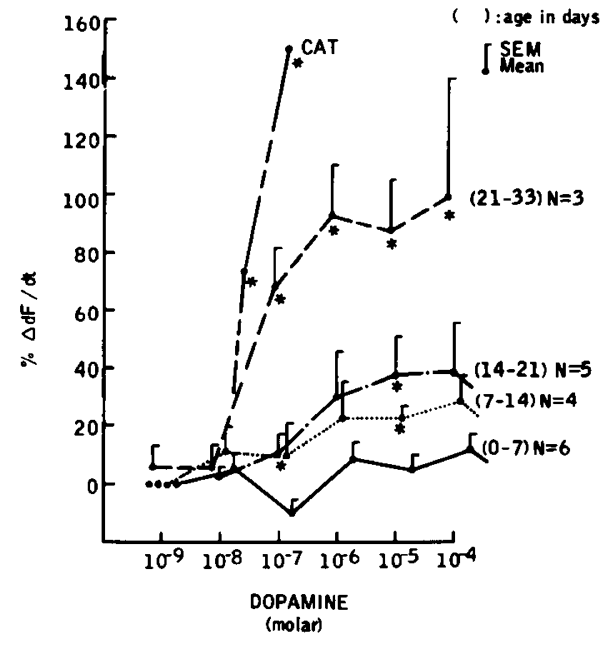

Fig. 1. Dose-response curves of puppy ventricles and adult cat ventricle treated with dopamine. There is an increasing inotropic-responsiveness with age of isolated puppy ventricle to dopamine. $\left({ }^{*}\right) P<$ 0.05 using puppies $0-7$ days old as control.

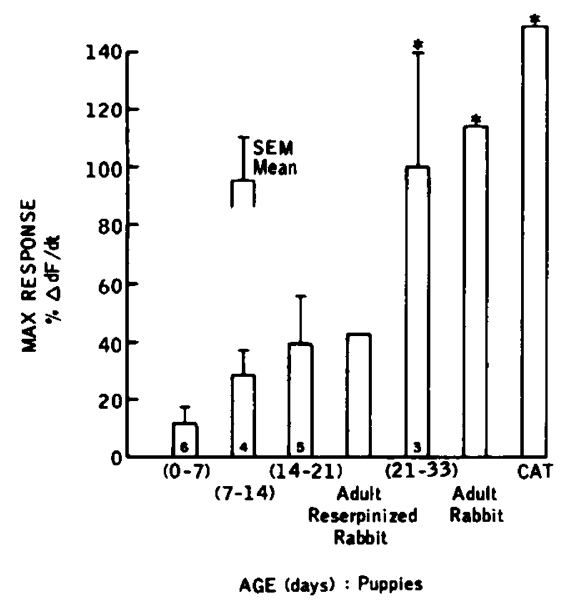

Fig. 2. Maximum response $(\% \Delta \mathrm{dF} / \mathrm{dt})$ of isolated ventricles of puppies, adult rabbit (untreated and pretreated with reserpine), and adult cat to dopamine. $\left({ }^{*}\right) P<0.05$ using puppies $0-7$ days old as control.

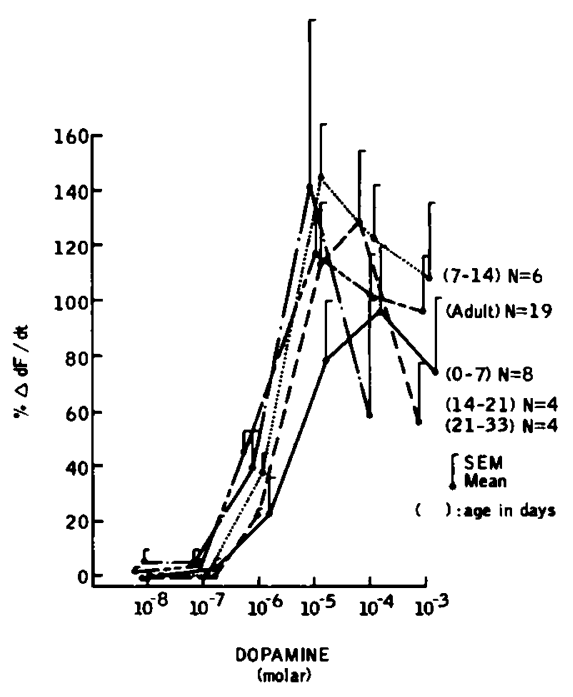

Fig. 3. Dose-response curves of puppy and adult dog atrial strips treated with dopamine. There is no apparent difference of the inotropic responsiveness of these atrial strips with increasing age.
The inotropic effect of dopamine and isoproterenol upon atrial strip preparations from adult dogs could be blocked partially by propranolol $\left(10^{-7} \mathrm{M}\right)$ but not by haloperidol $(1.33$ $\times 10^{-7} \mathrm{M}$ to $2 \times 10^{-6} \mathrm{M}$, Figs. 4 and 5).

The maximum percentage change of $\mathrm{dF} / \mathrm{dt}$ was greater when a fresh solution of dopamine prepared from dopamine hydrochloride crystals was used than when commercially available dopamine solution containing $1 \%$ sodium bisulfite was used. Sodium bisulfite alone produced a negative inotropic effect at a concentration equivalent to that obtained by $10^{-3}$ concentration of commercially available dopamine.

\section{DISCUSSION}

The cardiovascular effects of dopamine may be mediated through the following mechanisms: 1) $\beta$-adrenergic receptor stimulation in the myocardium; 2) slight $\alpha$-receptor stimulation in peripheral vasculature; 3 ) indirect stimulation of $\beta$-receptors through release of norepinephrine from sympathetic nerve endings; 4) "dopaminergic receptor" stimulation in the renal, mesenteric, coronary, and cerebral beds; and 5) through metabolic conversion to norepinephrine $(1,2,4,13-15)$.

It has been shown by a number of investigators that neonatal ventricular myocardial tissue of dog, rabbit, and rat does not receive its adult complement of sympathetic nerve endings until approximately 3 weeks of age $(5-7,9,17)$, whereas myocardial tissue of swine and lambs receives its full complement of

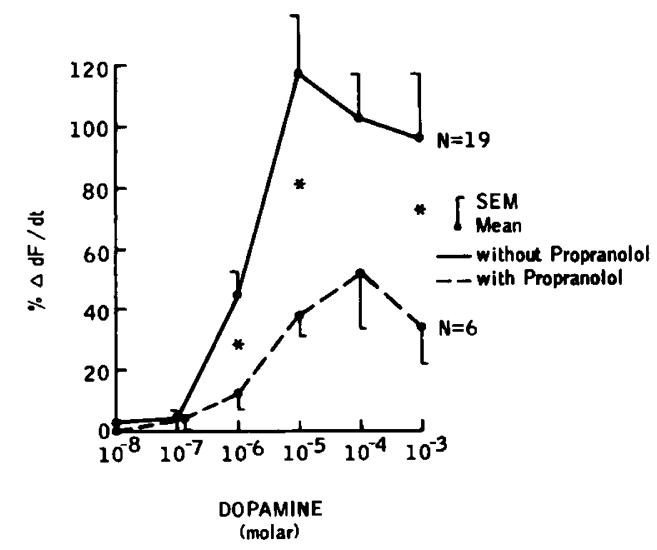

Fig. 4. Dose response curves of adult dog atrial strips bathed with dopamine. Experiments were performed with and without $\beta$-adrenergic receptor blockade by propranolol. $\left({ }^{*}\right) P<0.05$.

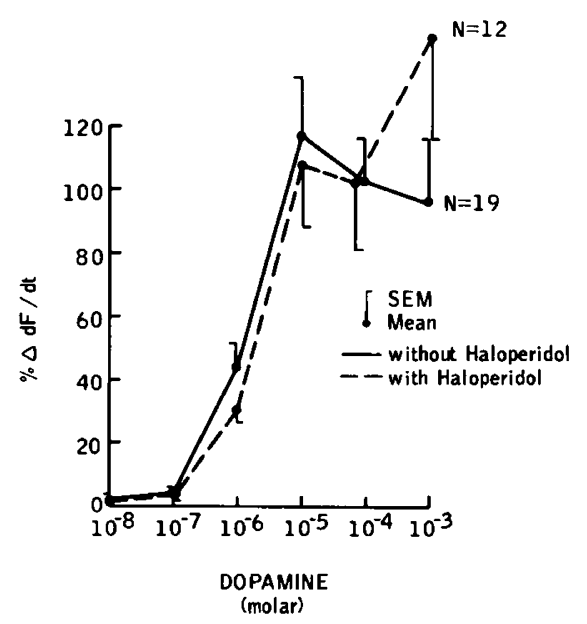

Fig. 5. Dose-response curves of adult dog atrial strips bathed with dopamine. Experiments were performed with and without "dopaminergic" receptor blockade by haloperidol. 
sympathetic nerve endings by about five days of age (5) Because of this relative lack of sympathetic innervation, ventricular myocardial levels of norepinephrine are reduced in the young animal (6). It follows, therefore, that decreased responsiveness of neonatal myocardial tissue to agents that act in part by releasing norepinephrine would be expected. The results of the isolated ventricle experiments in this study are consistent with this hypothesis. The maximum percentage change of $\mathrm{dF} / \mathrm{dt}$ increased from $12 \pm 5$ at $0-7$ days of age to $100 \pm 40$ at more than 21 days of age. This increasing responsiveness parallels the increasing responsiveness with age to tyramine and $\mathrm{X} 537 \mathrm{~A}$ which Gillette et al. (8) reported previously from this laboratory. The similarity of the dopamine dose-response curve of the reserpinized rabbit ventricle to that of the young puppy ventricle and that of the nonreserpinized rabbit to the older puppy ventricle also suggests that the difference in responsiveness is secondary to differences in availability of releasable norepinephrine. Recognizing the pitfalls of comparing responses among species, adult rabbit and cat ventricle were used because they are comparable in size to puppy ventricle.

Alternate explanations for the increasing responsiveness of puppy ventricle with increasing age to dopamine include a maturational change in the quality or number of myocardial $\beta$ adrenergic receptors, a relative increase in the number of contractile elements in the myocardium $(5,6)$, or age-related development of dopamine $\beta$-oxidase activity. Failure to demonstrate an age-related difference in response to isoproterenol, however, renders the first two possibilities unlikely. A maturational change of dopamine $\beta$-oxidase activity could account for the age-related difference in response to dopamine if exogenously administered dopamine resulted in increased synthesis of norepinephrine. However, based on experiments using the dopamine $\beta$-oxidase inhibitor, disulfiram, Tsai et al. (19) concluded that increased synthesis of norepinephrine was an insignificant mechanism in the action of dopamine.

The fact that atrial strips from young puppies respond to the inotropic effects of dopamine at an earlier age than ventricle is consistent with the concept that atrial sympathetic innervation occurs before ventricular sympathetic innervation $(5,17)$. To demonstrate that dopamine acts directly or indirectly upon the $\beta$-adrenergic receptor but not upon a "dopaminergic receptor" in the myocardium, the drug was evaluated after the addition of propranolol or haloperidol. The effect of dopamine was blocked by propranolol but was unaffected by haloperidol.

Fresh dopamine solution prepared from crystals of dopamine hydrochloride produced a greater increase in $\mathrm{dF} / \mathrm{dt}$ than did commercially available dopamine containing $1 \%$ sodium bisulfite. Furthermore, sodium bisulfite $(0.052 \mathrm{M})$ alone produced a negative inotropic effect. This is the concentration of sodium bisulfite in $10^{-3} \mathrm{M}$ dopamine preparations containing $1 \%$ sodium bisulfite. This effect, however, is probably not of clinical significance since $10^{-3} \mathrm{M}$ blood levels of dopamine are probably not attained therapeutically.

Although isolated perfused immature ventricle from puppies responded differently to dopamine than the mature ventricle, this may not be the case with immature ventricle in situ. Furthermore, since the age at which sympathetic innervation is complete in the human is unknown, this data cannot be extrapolated to human neonates. Careful observation of the clinical effects of dopamine in children will be necessary, with special emphasis on the response of neonates to the inotropic effect of the drug.

\section{CONCLUSION}

This study demonstrates an age-related variation of response of isolated puppy ventricle to dopamine. No age-related variation in response was demonstrated using isolated atrial strip preparations. Both isolated ventricle and atrial strip preparations were equally responsive to isoproterenol at all ages tested.

\section{REFERENCES AND NOTES}

1. Bülbring, E., and Burn, J. H.: The action of tyramine and adrenalin on the denervated nictitating membrane. J. Physiol., 91:459 (1938).

2. Chiba, S.: Pharmacological analysis of dopamine action on the isolated dog atrium. Tohoku J. Exp. Med., I15: 355 (1975).

3. Dopamine for treatment of shock. Med. Lett., 17: 13 (1975)

4. Farmer, J. B.: Indirect sympathomimetic actions of dopamine. J. Pharm. Pharmacol., 18: 261 (1966)

5. Friedman, W. F.: The intrinsic physiological properties of the developing heart. In: Neonatal Heart Disease (Grune and Stratton, New York, 1973).

6. Friedman, W. F., Pool, P. E., Jacobowitz, D.,Seagren, S. C., and Braunwald, E.: Sympathetic innervation of the developing rabbit heart. Circ. Res., 23. 25 (1968).

7. Geis, W. B., Tatooles, C. J., Priola, D. V., and Friedman, W. F.: Factors influencing neurohumeral control of the heart in the newborn dog. Amer. J. Physiol., 228: 1685 (1975).

8. Gillette, P. C., Munson, R. G., Lewis, R. M., and Schwartz, A.: Response of the neonatal heart to a new inotropic agent RO-2-2985 (X5371) Pediat. Res., 10: 570 (1976).

9. Glowinski, J., Axelrod, J., Kopin, I., and Wurtman, R.: Physiological disposition of $\mathrm{H}^{3}$-norepinephrine in the developing rat. J. Pharmacol. Exp Ther., 146: 48 (1964).

10. Goldberg, L.: Cardiovascular and renal actions of dopamine: Potential clinical applications. Pharmacol. Rev., 24: 1 (1972).

11. Goldberg, L. I.: Dopamine-clinical uses of an endogenous catecholamine. N. Engl. J. Med., 291: 707 (1974).

12. Lebowitz, E. A., Norick, J. S., and Rudolph, A. M.: Development of myocardial sympathetic innervation in the fetal lamb. Pediat. Res., 6: 887 (1972).

13. Lee, W. C., and Yoo, C. S.: Mechanism of cardiac activities of sympathomimetic amines on isolated auricles of rabbits. Arch. Inst. Pharmacodyn., 151: 93 (1964).

14. Oxawa, H., Aibara, H., and Sasajima, M.: Effects of dopamine on the isolated left atrium in the rat. Folia Pharmacol. Japon, 70: 399 (1974).

15. Reid, P. R., and Thompson, W. L.: The clinical use of dopamine in the treatment of shock. Johns Hopkins Med. J., 137: 276 (1975).

16. Sheldon, C. A. Friedman, W. F., and Sybers, H. D.: Scanning electron microscopy of fetal and neonatal lamb cardiac cells. J. Mol. Cell. Cardiol., 8: 853 (1976).

17. Sinha, S. N., Armour, J. A., and Randall, W. C.: Development of autonomic innervation of the heart. [Abstr.] Circulation (Suppl. IV), 48: IV-37 (1973).

18. Winslow, E. J., Loeb, H. S., Rahimtoola, S. H., Kamath, S., and Gunnar, $R$.: Hemodynamic studies and results of therapy in 50 patients in bacteremic shock. Amer. J. Med., 54: 421 (1973).

19. Tsai, T. H., Langer, S. Z., and Trendelenburg, U.: Effects of dopamine and a-methyl-dopamine on smooth muscle and on the cardiac pacemaker. J. Pharmacol. Exp. Ther., 156: 310 (1967).

20. This research was supported in part by a grant from Withrow Wier and John Caldwell Meeker, by a grant from Arnar-Stone Laboratories, Inc., and by Grants HL-5756 and HL 07219 from the NIH, USPHA

21. This research was presented in part at the Southern Society for Pediatric Research Meeting, Pharmacology Section, New Orleans, Louisiana, January 28,1977

22. Requests for reprints should be addressed to: David J. Driscoll, M.D., Texas Children's Hospital, 6621 Fannin, Houston, TX 77030 (USA).

23. Received for publication January $27,1977$.

24. Accepted for publication May 6,1977 . 